\title{
Relationship between serotonin transporter gene polymorphisms and platelet serotonin transporter sites among African-American cocaine-dependent individuals and healthy volunteers.
}

\author{
Ashwin A. Patkar \\ Thomas Jefferson University \\ Wade H. Berrettini \\ University of Pennsylvania \\ Paolo Mannelli \\ Thomas Jefferson University \\ Follow this and additional works at: https://jdc.jefferson.edu/phbfp \\ Reman Gopalakrishnan \\ i. Phastsofethersekibiativersitymons \\ bet us know how access to this document benefits you \\ Max Delbruck Center for Molecular Medicine

\section{Recommended Citation} \\ Patkar, Ashwin A.; Berrettini, Wade H.; Mannelli, Paolo; Gopalakrishnan, Raman; Hoehe, Margret \\ Re: Bilal, Louai; Weinstein, Stephen; and Vergare, Michael J., "Relationship between serotonin \\ transporter gene polymorphisms and platelet serotonin transporter sites among African- \\ American cocaine-dependent individuals and healthy volunteers." (2004). Department of \\ Psychiatry and Human Behavior Faculty Papers. Paper 45. \\ https://jdc.jefferson.edu/phbfp/45 \\ This Article is brought to you for free and open access by the Jefferson Digital Commons. The Jefferson Digital \\ Commons is a service of Thomas Jefferson University's Center for Teaching and Learning (CTL). The Commons is \\ a showcase for Jefferson books and journals, peer-reviewed scholarly publications, unique historical collections \\ from the University archives, and teaching tools. The Jefferson Digital Commons allows researchers and interested \\ readers anywhere in the world to learn about and keep up to date with Jefferson scholarship. This article has been \\ accepted for inclusion in Department of Psychiatry and Human Behavior Faculty Papers by an authorized \\ administrator of the Jefferson Digital Commons. For more information, please contact: \\ JeffersonDigitalCommons@jefferson.edu.
}


Authors

Ashwin A. Patkar, Wade H. Berrettini, Paolo Mannelli, Raman Gopalakrishnan, Margret R. Hoehe, Louai Bilal, Stephen Weinstein, and Michael J. Vergare 


\section{Relationship between serotonin transporter gene polymorphisms and platelet serotonin transporter sites among African-American cocaine-dependent individuals and healthy volunteers}

Alterations in the serotonin transporter (5-HTT) have been implicated in a variety of psychiatric disorders including cocaine dependence. A polymorphism in the promoter region of the serotonin transporter gene (5-HTTLPR) appears to influence the expression of 5-HTT in human cell lines. We investigated whether 5-HTTLPR variants were related to differences in measures of platelet 5-HTT sites in cocaine-dependent patients and healthy volunteers (controls). Polymerase chain reaction-based genotyping of a 44 base pair insertion/deletion polymorphism in 5-HTTLPR was performed in 138 cocaine-dependent African-American subjects and 60 African-American controls. This yielded a short (S) and a long (L) allele. Platelet 5-HTT sites were measured using the tritiated paroxetine binding assay. Relationships of 5-HTTLPR genotypes with $\mathrm{B}_{\max }$ (density of serotonin transporter) and $\mathrm{K}_{\mathrm{d}}$ (affinity constant) were examined. $\mathrm{B}_{\max }$ values were significantly lower in cocaine-dependent patients $(640+/-233)$ than controls $(906+/-225)(\mathrm{P}<0.001)$; however, 5-HTTLPR genotype distributions or allele frequencies did not differ between the two groups. There were no significant differences in $\mathrm{B}_{\max }$ between the three genotypes among cocaine-dependent patients $(\mathrm{LL}=690+/-246, \mathrm{LS}=620+/-235$, SS=587+/183; $\mathrm{P}=0.14$ ) or controls ( $\mathrm{LL}=909+/-233, \mathrm{LS}=938+/-279, \mathrm{SS}=866+/-143 ; \mathrm{P}=0.65)$. All three genotypes in cocaine-dependent patients showed comparable reductions in $\mathrm{B}_{\max }$ from the corresponding genotypes in controls. Demographic variables, severity of substance use or depression were unrelated to $\mathrm{B}_{\max }$ or 5-HTTLPR genotypes. Although platelet 5-HTT densities are reduced in patients with cocaine dependence compared with healthy volunteers, these genotypic variations in the serotonin transporter do not seem to influence levels of platelet 5HTT in cocaine-dependent patients or healthy volunteers.

\section{Introduction}

Considerable preclinical evidence indicates that serotonergic (5-HT) mechanisms may mediate the central effects of cocaine (McMahon and Cunningham, 2001). Acutely, cocaine is found to inhibit 5-HT uptake (Cunningham et al., 1996; Castanon et al., 2000), while repeated administration of cocaine has been shown to reduce 5-HT levels in neurons (Heidbreder et al., 1999). Alterations in 5-HT activity also modulate cocaine withdrawal (Baumann and Rothman, $\underline{1998)}$ ) and influence cocaine-induced expression of early genes in the brain (Humblot et al., 1998). Moreover, manipulations of the 5-HT system may influence rates of cocaine selfadministration among animals (Kleven and Koek, 1998). Relatively limited data are available regarding 5-HT function in cocaine-dependent individuals, but the findings support animal studies. For example, studies have reported impaired hormonal responses to 5-HT agents among cocaine-dependent patients compared with controls (Buydens-Branchey et al., 1997;

Handelsman et al., 1998).

Among the various components of the 5-HT system, the serotonin transporter (5-HTT) is critically important in regulating the reuptake of 5-HT into the presynaptic neuron and the 
platelet, and serves as a target site for certain antidepressants (Graham and Langer, 1992; Schloss and Williams, 1998). High affinity binding of the cocaine analogue $\left[{ }^{125}\right.$ I]RTI-55 to the 5-HTT sites in human brain has been demonstrated (Staley et al., 1994). Moreover, changes in 5-HTT have been reported in neuroimaging and post-mortem studies of cocaine-abusing individuals (Little et al., 1998; Jacobsen et al., 2000). The human 5-HTT protein is found to be encoded by a single gene, and a functional biallelic repeat polymorphism in the 5' promotor region of 5-HTT (5-HTTLPR) yielding a short (S) and a long (L) variant of the allele has been reported (Lesch et al., 1994; Gelernter et al., 1995). The S variant has been found to exert a dominant effect and is associated with reduced transcriptional efficiency resulting in reduced 5HTT expression in lymphoblasts (Heils et al., 1996; Lesch et al., 1996). Studies of the 5HTTLPR polymorphism in substance abusers have yielded conflicting results. While 5HTTLPR variants have been associated with alcoholism in some studies (Sander et al., 1997;

Schuckit et al., 1999; Lichtermann et al., 2000), other studies of substance abusers have not confirmed the association (Berrettini and Persico, 1996; Patkar et al., 2001; Kranzler et al., $\underline{2002}$ ).

Investigations of the influences of 5-HTTLPR genotypes on the expression of the 5-HTT in human platelets and neurons have not been consistent. While the short variant has been found to be associated with reduced platelet binding $\left(\mathrm{B}_{\mathrm{max}}\right)$ (Stoltenberg et al., 2002) and reduced platelet uptake ( $\left.\mathrm{V}_{\max }\right)$ (Hanna et al., 1998; Greenberg et al., 1999), other investigators have reported no effect of the genotypes on both $\mathrm{V}_{\max }$ (Kaiser et al., 2002) and $\mathrm{B}_{\max }$ (Greenberg et al., 1999;

Preuss et al., 2000). Similarly, reports of a relationship between the 5-HTTLPR genotype and in vivo 5-HTT availability that was observed in a neuroimaging study of healthy subjects (Heinz et al., 2000) could not be replicated in a similarly designed study (Willeit et al., 2001).

Most studies investigating the relationship of 5-HTTLPR genotypes with the expression of 5HTT have primarily recruited individuals of European background and investigated alcohol dependence. There are relatively limited published data among African-American healthy volunteers as well as among cocaine abusers, a major public health problem that particularly affects minority populations. In a previous smaller sample we had observed that AfricanAmerican cocaine-dependent persons had significantly reduced platelet 5-HTT densities compared with controls (Patkar et al., 2003). Since the density of platelet 5-HTT sites may be influenced by genetic variations in the 5-HTTLPR, we first compared platelet 5-HTT between cocaine-dependent patients and controls, and then investigated whether the platelet 5-HTT densities were different among the 5-HTTLPR genotypes in patients with cocaine dependence and controls. Finally, we examined each genotype of cocaine and control group with respect to platelet 5-HTT measures to determine whether cocaine-associated alterations in 5-HTT occur across all 5-HTTLPR genotypes.

\section{Subjects}

The data was collected from September 1997 to February 2002. One hundred and thirty-eight subjects were recruited from individuals attending a university-affiliated, outpatient substance abuse treatment program in Philadelphia. The study was annually approved by the Institutional Review Board of Thomas Jefferson University, Philadelphia. Following a description of the study, informed consent was obtained. The Structured Clinical Interview for DSM-IV Axis I Disorders (First et al., 1997) was then administered. Subjects also underwent a medical history 
review and physical examination. Exclusion criteria included a diagnosis of schizophrenia, major depression, bipolar disorder, or schizoaffective disorder, having a serious medical illness, pregnancy, and receiving psychotropic medications. If subjects used more than one substance, they were included if their primary drug was cocaine. Urine drug screens were obtained for all subjects.

Nearly $90 \%$ of the patients in the program were African-American. The sample was restricted to African-American subjects to represent the clinical population and to reduce possible ethnic variations in allele frequencies. Only subjects who had a history of substance abuse in one or more immediate family members, who reported cocaine use in the previous 30 days on the Addiction Severity Index (ASI), and who had onset of regular cocaine use before 25 years of age were included. The family history was elicited by items on the family history section of the ASI. The sample was restricted to individuals with early onset of regular cocaine use, inability to sustain abstinence, and having one or more first-degree affected relatives to define a subset of cocaine-dependent patients whose addiction may be more likely to influenced by genetic factors (McGue et al., 1992).

Sixty consenting African-American controls were recruited from those responding to local advertisements. Control subjects were screened using the Structured Clinical Interview for DSM-IV Axis I disorders, urine drug screens, medical and family history review and physical examination. They were excluded if they had a current or past history of substance abuse (except tobacco), a major psychiatric disorder (schizophrenia, major depression or bipolar disorder), serious medical disorders, a positive urine drug screen, were pregnant or were taking psychotropic medications.

\section{Assessments}

Subjects and controls were assessed using the Beck Depression Inventory (BDI) (Beck and Steer, 1987), and the ASI (McLellan et al., 1992). The ASI was performed only on cocainedependent subjects. The BDI is a widely-used, self-report questionnaire that assesses depressive symptomatology during the previous week and requires about $10 \mathrm{~min}$ to complete. The ASI is a 40-min structured interview that has been extensively used for clinical and research purposes. It assesses problem severity in seven domains of functioning: drug use, alcohol use, employment/support, medical, legal, family/social and psychiatric. For each domain, a composite score that ranges from 0 (minimum) to 1 (maximum) is provided to assess the adequacy of functioning in these areas during the previous 30 days.

\section{Genotyping}

Genomic DNA was isolated from anticoagulated venous blood using standard techniques (Miller et al., 1988). Genotyping for a 44 base pair insertion/deletion polymorphism in the 5' promotor region was performed as described by Heils et al. (1996). Briefly, the 5-HTTLPR region was amplified using polymerase chain reaction with oligonucleotide primers $\left(5^{\prime}-\right.$ GGCGTTGCCGCTCTGAATTGC and 5'-GAGGGACTGAGCTGGACAACCCAC) to generate a 484 base pair (S) or a 528 base pair (L) fragment. The amplified fragments were separated on agarose gels, and bands were visualized by ethidium bromide staining and 
ultraviolet illumination. Genotypes were evaluated by investigators who were blind to the status of the subject and any discrepancies were resolved by test replication.

\section{$\left[{ }^{3} \mathrm{H}\right]$ Paroxetine binding assay}

After a minimum of 2 weeks of abstinence from cocaine, $20 \mathrm{ml}$ venous blood was collected in ethylendiamine tetraacetic acid-containing tubes at room temperature and processed within $4 \mathrm{~h}$ to harvest platelets. The platelet pellets were immediately frozen at -80 [degrees]C until they were assayed. Women were studied in the initial follicular phase of the menstrual cycle. Paroxetine binding was performed using techniques described previously (Ozaki et al., 1994). Protein concentrations were determined by the method of Lowry et al. (1951). Specific binding of $\left[{ }^{3} \mathrm{H}\right]$ paroxetine binding (Life Science Products Inc, Boston, MA, USA) was determined at six different concentrations in the presence and absence of fluoxetine (Sigma Labs, St Louis, MO, USA). The intra-assay and interassay coefficients of variation for $\mathrm{B}_{\max }$ were $3.6 \%$ and $9.2 \%$, respectively. The scatchard analysis of the platelet $\left[{ }^{3} \mathrm{H}\right]$ paroxetine binding was performed using the LIGAND software program to determine transporter densities $\left(\mathrm{B}_{\max }\right)$ and affinity constant $\left(\mathrm{K}_{\mathrm{d}}\right)$. The $\mathrm{B}_{\max }$ was expressed as fentomoles per milligram of protein while the $\mathrm{K}_{\mathrm{d}}$ was expressed as nanomoles per liter. The laboratory personnel were blind to the clinical data.

\section{Statistical analyses}

The allele frequencies and genotype distributions of the 5-HTTLPR variants were calculated for cocaine-dependent patients and controls. Chi-square tests were used to compare allele frequencies with those predicted by Hardy-Weinberg equilibrium based on allele frequencies reported by Lesch et al. (1996). $\mathrm{B}_{\max }$ and $\mathrm{K}_{\mathrm{d}}$ values were compared between cocaine-dependent patients and controls, and between different genotypes of cocaine-dependent patients using $t$ tests (two-tailed) with corrections for unequal variances where necessary or one-way analysis of variance (ANOVA) as appropriate. Correlations between variables were performed using Pearson product moment or point biserial correlations as appropriate. All calculations were performed using SPSS 11.0 software.

\section{Power considerations}

We tested the hypothesis that there was a functional difference in the 5-HTTLPR variants as measured by $\left[{ }^{3} \mathrm{H}\right]$ paroxetine binding in cocaine-dependent subjects and controls. We initially computed the power to detect significant differences in $\mathrm{B}_{\max }$ between subjects and controls based on our previous studies of 5-HTT in cocaine-dependent patients and controls (Patkar et al., 2003). With two-tailed alpha set at 0.05 , the power to detect between-group differences in $\mathrm{B}_{\max }$ in the current sample of 139 cocaine-dependent subjects and 60 controls was 0.99 (adjusted $\mathrm{r}^{2}=0.19$ ). The next set of analyses involved calculating the power to detect a relationship between $B_{\max }$ and 5-HTTLPR genotypes. Since we could not find published data in cocaine-dependent patients, we relied on literature that found a significant relationship of 5HTTLPR genotypes with platelet 5-HTT binding in 54 alcoholic persons (Stoltenberg et al., 2002). In this study the effect size (f) was strong (>0.4) as defined by Cohen (1988). We 
assumed a more conservative effect size $(\mathrm{f}=0.30)$ for our study. With two-tailed alpha set at 0.05 , and degrees of freedom at 2, the current study had a power of 0.86 and 0.99 to detect main effects of the 5-HTTLPR genotype on 5HTT binding in 60 controls and 138 cocaine-dependent patients, respectively. Based on these power considerations, we anticipated our sample size would be sufficient to be able to address the research questions of the study.

\section{Results}

Sample

From a total of 212 African-American cocaine-dependent subjects and 108 controls who were screened, 138 subjects and 60 controls fulfilled the inclusion criteria and had blood samples analyzed for 5-HTT binding and 5-HTTLPR genotypes. The subjects (71\% male) and controls $\left(61 \%\right.$ male) did not differ significantly in gender $\left([\mathrm{chi}]^{2}=2.16\right.$, degrees of freedom $\left.=1, \mathrm{P}=0.23\right)$. However, subjects $(36.11+/-6.12$ were significantly older than controls $(32.60+/-5.74)(\mathrm{t}=3.88$, degrees of freedom=196, $\mathrm{P}<0.001)$. Also, subjects $(84 \%)$ were significantly more likely to be unemployed compared with controls $(29 \%)\left([\mathrm{chi}]^{2}=39.9\right.$, degrees of freedom $\left.=1, \mathrm{P}<0.001\right)$. Similarly, significant differences were observed between subjects (74\% single) and controls $(46 \%$ single $)$ in marital status $\left([\mathrm{chi}]^{2}=6.18\right.$, degrees of freedom $\left.=1, \mathrm{P}<0.01\right)$. Cocaine-dependent subjects scored significantly higher on the BDI (11.84+/-7.7) than controls $(6.24+/-3.43)$ $(\mathrm{t}=5.26$, degrees of freedom $=196, \mathrm{P}<0.001)$. The mean age of first drug use was $20.3+/-4.2$ years. Cocaine-dependent subjects had used cocaine for 15.5+/-7.7 years, the average use was $5.7+/-1.7$ rocks per day. Over $80 \%$ used cocaine on a daily basis. The ASI composite scores in various domains were as follows: medical $(0.07+/-0.17)$, employment $(0.87+/-0.28)$, drug $(0.24+/-0.21)$, alcohol $(0.23+/-0.22)$, legal $(0.04+/-0.15)$, family $(0.13+/-0.20)$ and psychiatric $(0.17+/-0.21)$. The admission urine drug screens for $35 \%$ of the patients was positive for cocaine, indicating that more than one-third patients were actively using cocaine at time of admission. Of the $63 \%$ of patients who were abstinent, the average length of abstinence prior to admission was 14.4 days. A significant proportion of the cocaine-dependent subjects had additional current and lifetime substance abuse and dependence diagnoses. About $53 \%$ had abused or were dependent on alcohol, approximately $82 \%$ were nicotine dependent, nearly $31 \%$ were abusing or dependent on marijuana, and about $15 \%$ had opioid abuse or dependence during their lifetime or at the present time.

\section{Platelet $\left[{ }^{3} \mathbf{H}\right]$ paroxetine binding in cocaine-dependent patients and controls}

Cocaine-dependent patients showed significantly lower $B_{\max }(639.71+/-234.32)$ than controls $(905+/-225.34)(\mathrm{t}=55.12$, degrees of freedom $=196, \mathrm{P}<0.001)$. However, there was no significant difference in $\mathrm{K}_{\mathrm{d}}$ values between patients $(0.24+/-0.21)$ and controls $(0.26+/-0.17)(\mathrm{t}=0.81$, degrees of freedom=196, $\mathrm{P}=0.42$ ), and the correlation between $\mathrm{B}_{\max }$ and $\mathrm{K}_{\mathrm{d}}$ values was not statistically significant $(\mathrm{r}=0.11, \mathrm{P}=0.19)$. The platelet counts did not differ significantly between the patients with cocaine dependence (206+/-30 B/l) and control subjects (230+/-40 B/l). Since the patients were significantly younger than the controls, we examined but found no significant correlation between age and $\mathrm{B}_{\max }(\mathrm{r}=0.11, \mathrm{P}=0.18)$. Similarly, no correlation was observed 
between paroxetine binding and demographic characteristics, including gender, employment and marital status (all [chi] $]^{2}<1.8, \mathrm{P}>0.05$ in each case). Also, there were no significant correlations between paroxetine $\mathrm{B}_{\max }$ and $\mathrm{BDI}$ scores $(\mathrm{r}=-0.12, \mathrm{P}=0.19)$. We then analyzed the data to determine whether the pattern of cocaine use was related to paroxetine binding. No significant correlations were observed between $\mathrm{B}_{\max }$ values on the one hand and quantity $(\mathrm{r}=0.04)$, frequency $(\mathrm{r}=-0.09)$ or duration of cocaine use $(\mathrm{r}=-0.10)$, or age of first drug use $(r=0.07)$ on the other $(\mathrm{P}>0.05$ in each case). We also examined and found no significant difference in $\mathrm{B}_{\max }$ between patients who were actively using cocaine at the time of admission (positive urine drug screens) and those who had negative admission urine drug screens $\left([\mathrm{chi}]^{2}=2.38\right)$. Also, no significant correlation was observed between length of abstinence and $\mathrm{B}_{\max }(\mathrm{r}=0.11, \mathrm{P}=0.26)$.

\section{Platelet $\left[{ }^{3} \mathrm{H}\right]$ paroxetine binding and 5-HTTLPR genotypes in cocaine-dependent patients}

The genotype distributions of the 5-HTTLPR polymorphisms among cocaine-dependent individuals are presented in Table 1. The allele frequencies were $\mathrm{L}=164(59.4 \%)$ and $\mathrm{S}=112$ $(40.6 \%)$. The genotype distribution for cocaine-dependent subjects $\left([\mathrm{chi}]^{2}=0.98\right.$, degrees of freedom $=2, \mathrm{P}=0.61$ ) did not depart from that predicted from the Hardy-Weinberg equilibrium (Lesch et al., 1996). ANOVA analyses revealed no significant differences in $\mathrm{B}_{\max }$ values between the LL, LS and SS genotypes $[\mathrm{F}(2,136)=2.03, \mathrm{P}=0.14]\left(\right.$ Table 1). Similarly, $\mathrm{K}_{\mathrm{d}}$ values were not significantly different among the three genotypes $[\mathrm{F}(2,136)=0.81, \mathrm{P}=0.44]$. We also analyzed the data by comparing the $\mathrm{B}_{\max }$ values in LL genotype $(690+/-246)$ with those in a combination of $\mathrm{L} / \mathrm{S}$ and $\mathrm{S} / \mathrm{S}$ genotype $(611+/-224)$, assuming a dominant effect of the $\mathrm{S}$ allele, and found no significant differences $(\mathrm{t}=1.71$, degrees of freedom=136, $\mathrm{P}=0.11)$. Similarly, $\mathrm{K}_{\mathrm{d}}$ values did not differ between the LL and LS+SS genotype groups $(\mathrm{t}=0.46$, degrees of freedom $=136, \mathrm{P}=0.48$ ). The distribution of $\mathrm{B}_{\max }$ among the three genotypes in cocainedependent patients is summarized in Figure 1.

No significant differences were observed in the distribution of sex among the different 5HTTLPR genotypes $\left([\mathrm{chi}]^{2}=1.36\right.$, degrees of freedom $\left.=2, \mathrm{P}=0.43\right)$. The data was also analyzed to determine whether the pattern of cocaine use was related to the transporter polymorphisms. No significant associations were found between the 5-HTTLPR genotypes on the one hand and admission urine drug screen $\left([\mathrm{chi}]^{2}=1.48\right.$, degrees of freedom $\left.=2, \mathrm{P}=0.43\right)$, quantity $(\mathrm{F}=0.45$, $\mathrm{P}=0.62)$, frequency $(\mathrm{F}=0.41, \mathrm{P}=0.66)$ or duration of cocaine use $(\mathrm{F}=0.37, \mathrm{P}=0.70)$, age of first drug use $(\mathrm{F}=0.82, \mathrm{P}=0.44)$ or length of abstinence $(\mathrm{F}=1.19, \mathrm{P}=0.21)$ on the other.

A significant proportion of the cocaine-dependent subjects had additional current and lifetime substance abuse and dependence diagnoses, reflecting the clinical population in urban treatment settings. However, no significant differences were found in 5-HTTLPR genotypes among patients with cocaine dependence alone and those with current or lifetime alcohol dependence and abuse (all $[\mathrm{chi}]^{2}<2.02, \mathrm{P}>0.05$ ). With respect to other major substances (opioid and marijuana) also, no relationship was observed between genotypes and Axis I substance use diagnoses (all $[\text { chi }]^{2}<1.65, \mathrm{P}>0.05$ ). 
Table 1

\begin{tabular}{lccc}
\hline 5-HTTLPR genotype & Cocaine-dependent subjects $(n=138)$ & $B_{\max }(\text { mean } \pm \text { standard deviation })^{\mathrm{a}}$ & $K_{\mathrm{d}}\left(\right.$ mean \pm standard deviation) ${ }^{\mathrm{b}}$ \\
\hline LL & $50(36.2 \%)$ & $690.18 \pm 246.52$ & $0.26 \pm 0.07$ \\
LS & $64(46.4 \%)$ & $620.65 \pm 235.72$ & $0.24 \pm 0.05$ \\
SS & $24(17.4 \%)$ & $586.65 \pm 182.95$ & $0.24 \pm 0.06$ \\
\hline
\end{tabular}

Allele frequencies, $L=164(59.4 \%)$ and $S=112(40.6 \%)$.

${ }^{a}$ Analysis of variance, $F(2,136)=2.03, P=0.14$.

${ }^{\mathrm{b}}$ Analysis of variance, $F(2,136)=0.81, P=0.44$.

Figure 1

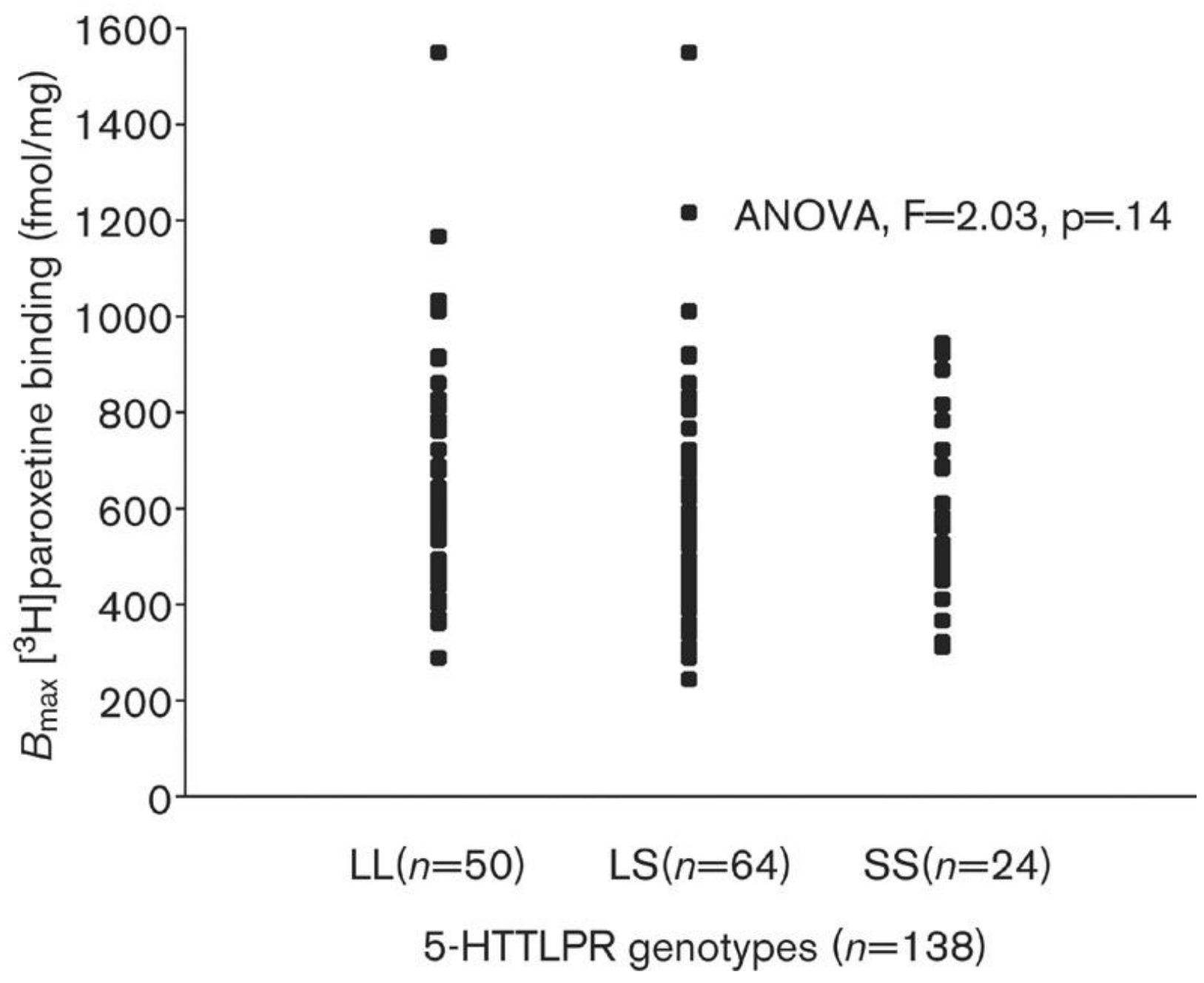




\section{Platelet $\left[{ }^{3} \mathrm{H}\right]$ paroxetine binding and 5-HTTLPR genotypes in controls}

Table 2 summarizes the genotype distributions of the 5-HTTLPR polymorphisms among controls. The allele frequencies were $\mathrm{L}=68(56.6 \%)$ and $\mathrm{S}=52(43.4 \%)$. There was no departure of the genotype distribution from that predicted from the Hardy-Weinberg equilibrium ([chi $]^{2}=0.43$, degrees of freedom $=2, \mathrm{P}=0.87$ ). Similar to findings among cocaine-dependent patients, controls showed no significant differences in $\mathrm{B}_{\max }[\mathrm{F}(2,58)=0.43, \mathrm{P}=0.65]$ or $\mathrm{K}_{\mathrm{d}}[\mathrm{F}(2$, $58)=0.45, \mathrm{P}=0.64$ ] between the LL, LS and SS genotypes (Table 2). When the LL genotype was compared with a combination of the $\mathrm{L} / \mathrm{S}$ and $\mathrm{S} / \mathrm{S}$ genotype, no significant differences were found in $\mathrm{B}_{\max }(\mathrm{LL}=934+/-242, \mathrm{LS}+\mathrm{SS}=922+/-218 ; \mathrm{t}=0.85$, degrees of freedom=58, $\mathrm{P}=0.39)$ or $\mathrm{K}_{\mathrm{d}}(\mathrm{t}=0.62$, degrees of freedom $=58, \mathrm{P}=0.47)$. The distribution of $\mathrm{B}_{\max }$ among the three genotypes in cocaine-dependent patients is summarized in Figure 2. There was no significant effect of gender $\left([\mathrm{chi}]^{2}=1.14, \mathrm{P}>0.05\right)$ on genotype distribution in controls.

Table 2

\begin{tabular}{lccc}
\hline $\begin{array}{c}5-H T T L P R \\
\text { genotype }\end{array}$ & $\begin{array}{c}\text { Control subjects } \\
(n=60)\end{array}$ & $\begin{array}{c}B_{\max }(\text { mean } \pm \text { stan- } \\
\text { dard deviation) }\end{array}$ & $\begin{array}{c}K_{\mathrm{d}} \text { (mean } \pm \text { stan- }^{\mathrm{a}} \\
\text { dard deviation) }^{\mathrm{b}}\end{array}$ \\
\hline LL & $17(28.3 \%)$ & $909.8 \pm 233.9$ & $0.27 \pm 0.07$ \\
LS & $34(56.7 \%)$ & $938.4 \pm 279.9$ & $0.25 \pm 0.09$ \\
SS & $9(15.0 \%)$ & $866.5 \pm 143.4$ & $0.24 \pm 0.05$ \\
\hline
\end{tabular}

Allele frequencies: $L=68(56.6 \%)$ and $S=52(43.4 \%)$.

${ }^{a}$ Analysis of variance, $F(2,58)=0.43, P=0.65$.

${ }^{\mathrm{b}}$ Analysis of variance, $F(2,58)=0.45, P=0.64$.

\section{Figure 2}

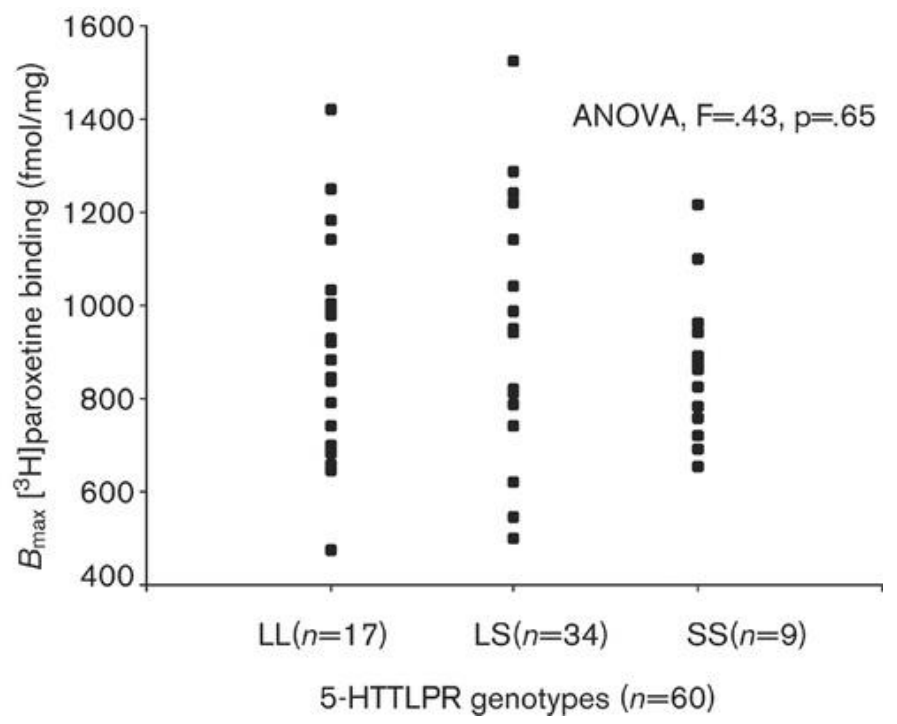


Finally, we compared the $\mathrm{B}_{\max }$ values of each genotype in cocaine-dependent patients with the corresponding genotype in controls (e.g. SS cocaine with SS controls). All three genotypes in cocaine-dependent patients showed comparable but significant reductions in $\mathrm{B}_{\max }$ from the corresponding genotypes in controls $(\mathrm{t}=4.21-5.28$, degrees of freedom $=31-96, \mathrm{P}<0.01$ in each case).

\section{Discussion}

The study examined the association of 5-HTTLPR polymorphisms with platelet 5-HTT measures in cocaine-dependent individuals and healthy volunteers. Contrary to our expectations, 5-HTTLPR polymorphisms did not seem to influence 5-HTT parameters expected to correlate with altered expression of the protein resulting from the polymorphism. The genotype distribution and allele frequencies in our sample were not significantly different from those reported among healthy volunteers (Lesch et al., 1996; Heinz et al., 2000) and alcoholic subjects (Heinz et al., 2000; Stoltenberg et al., 2002).

Our results differ from findings from in vitro experiments (Lesch et al., 1996), platelet studies (Stoltenberg et al., 2002), Single Photon Emission Computerized Tomography (SPECT) investigations (Heinz et al., 2000) and postmortem studies (Little et al., 1998) indicating that 5HTTLPR genotypes may influence the 5-HTT expression in healthy volunteers and substance abusers. In contrast to a 40-100\% difference in mean densities of 5-HTT between LL homozygotes and S-carriers that was observed in some of these studies (Lesch et al., 1996; Stoltenberg et al., 2002), we found the corresponding values to differ by about $2 \%$ in controls and about $11 \%$ in cocaine-dependent subjects. There could be several explanations for the discrepant findings. Our power calculations were based on a relatively limited sample from the literature $(\mathrm{n}=54)$ (Stoltenberg et al., 2002) and a type II error remains a possibility, because the presumed effect size of the polymorphism may differ across various populations. Differences in sample characteristics could be another explanation. Most of the studies have recruited individuals of European background while our sample consisted entirely of African-American individuals; the 5-HTTLPR alleles have been reported to be distributed differently across ethnic groups (Lerman et al., 1998). Another reason could be differences in the 5-HTT binding technique. For example, both Lesch's and Stoltenberg's groups used [ $\left.{ }^{125} \mathrm{I}\right] \mathrm{RTI}-55$ as a radioligand, while we employed $\left[{ }^{3} \mathrm{H}\right]$ paroxetine for binding purposes. It is also possible that modulation of the 5-HTT expression by the 5-HTTLPR polymorphism may not be detectable in the presence of other influences on platelet 5-HTT regulation such as second messenger systems and post-translational modifications (Greenberg et al., 1999; Zahniser and Doolen, 2001). Finally, gene sequences other than those within the 5-HTTLPR may also regulate transcription and affect 5-HT uptake (Flattem and Blakely, 2000; Kaiser et al., 2002).

It is worth noting that several well-designed studies involving reasonably sized samples have failed to detect an association between platelet 5-HTT and 5-HTTLPR polymorphic variants among healthy volunteers (Greenberg et al., 1999), individuals with obsessive compulsive disorder (Hanna et al., 1998), unipolar and bipolar patients (Mellerup et al., 2001), and autistic persons (Anderson et al., 2002). Our findings lend additional support to the negative literature. The data are also consistent with a neuroimaging study of healthy volunteers that found no association between 5-HTT availability and 5-HTTLPR polymorphisms (Willeit et al., 2001) and similar results in postmortem brains of schizophrenic patients (Naylor et al., 1998). The 
conflicting data in this area indicate that the pattern of 5-HTTLPR effects may vary in different populations and environments (Stoltenberg and Burmeister, 2000).

All three genotypes in patients with cocaine dependence showed significant reductions in $\mathrm{B}_{\max }$ from controls. Reduced platelet 5-HTT has been reported in several psychiatric disorders including depression (Nemeroff et al., 1994) and alcoholism (Arranz et al., 1999). The question whether the reduction in platelet 5-HTT densities among cocaine-dependent persons represent trait or state phemonena remains unsettled. While we did not find an effect of 5-HTTLPR genotypes on the platelet 5-HTT, we also failed to find an association between measures of cocaine use and 5-HTT. Other studies have found an association of 5-HTTLPR with alcoholism (Sander et al., 1997) and with response to alcohol (Schuckit et al., 1999). Given the limited data in this area, more research is required to clarify whether 5-HTT alterations in substance abuse may be related to genotypic variations.

Certain limitations of our study deserve comment. First, reflecting the clinical population, cocaine-dependent individuals abused a variety of other substances; moreover, a high proportion of patients and controls smoked tobacco. The additional substance use may have affected platelet 5-HTT binding data. Second, there are potential problems of using volunteers recruited from advertisements as controls, such as demographic differences and high rates of personal and family histories of various illnesses (Adami et al., 2002). Third, although we studied patients after 2 weeks of abstinence, this cannot exclude the effects of chronic cocaine use on platelet 5-HTT sites. Fourth, while we excluded current Axis I disorders, Axis II psychopathology was not assessed. Finally, it is possible that platelet 5-HTT may not mirror 5HTT sites in the brain even though the same gene encodes for the 5-HTT on platelets and neurons (Lesch et al., 1993).

In conclusion, the present study could not detect an association between 5-HTTLPR genotypes and densities of platelet 5-HTT among African-American cocaine-dependent individuals and healthy volunteers. While platelet 5-HTT densities were reduced in cocaine-dependent persons from controls, the reduction was comparable across the three genotypes. Considering the evidence implicating the 5-HT system in cocaine dependence, further studies, preferably using well-defined populations, are required to clarify the genetic influences on 5-HTT expression.

\section{Acknowledgments}

The authors thank Cheryl Marshall for technical assistance and Edward Gottheil for manuscript review.

\section{References}

Adami H, Elliott A, Zetlmeisl M, McMahon R, Thaker G 2002. Use of telephone screens improves efficiency of healthy subject recruitment. Psychiatry Res 113:295-301.

Anderson GM, Gutknecht L, Cohen DJ, Brailly-Tabard S, Cohen JH, Ferrari P, et al. 2002. Serotonin transporter promoter variants in autism: functional effects and relationship to platelet hyperserotonemia. Mol Psychiatry 7:831-836. 
Arranz B, Rosel P, Sarro S, Zaldivar E, Cano R, Navarro M, et al. 1999. Platelet serotonergic binding sites in alcohol-dependent patients. Alcohol Alcohol 34:726-732.

Baumann MH, Rothman RB 1998. Alterations in serotonergic responsiveness during cocaine withdrawal in rats: similarities to major depression in humans. Biol Psychiatry 44:578-591.

Beck AT, Steer RA 1987. Beck Depression Inventory. San Antonio, TX: The Psychological Corporation. Brace and Jovanovich, Harcourt.

Berrettini WH, Persico AM 1996. Dopamine D2 receptor gene polymorphisms and vulnerability to substance abuse in African-Americans. Biol Psychiatry 40:144-147.

Buydens-Branchey L, Branchey M, Fergeson P, Hudson J, McKernin P 1997. The metachlorophenylpiperazine challenge test in cocaine addicts: hormonal and psychological responses. Biol Psychiatry 41:1071-1086.

Castanon N, Scearce-Levie K, Lucas JJ, Rocha B, Hen R 2000. Modulation of the effects of cocaine by 5-HT1B receptors: a comparison of knockouts and antagonists. Pharmacol Biochem Behav 67:559-566.

Cohen J 1988. Statistical Power Analysis for the Social Sciences. New York: Academic Press.

Cunningham KA, Bradberry CW, Chang AS, Reith ME 1996. The role of serotonin in the actions of psychostimulants: molecular and pharmacological analyses. Behav Brain Res 73:93102.

First MB, Spitzer RL, Gibbon M, Williams JBW 1997. Structured Clinical Interview for DSMIV Disorders (SCID-IV). Washington, DC: American Psychiatric Press.

Flattem NL, Blakely RD 2000. Modified structure of the human serotonin transporter promoter. Mol Psychiatry 5:110-115.

Gelernter J, Pakstis AJ, Kidd KK 1995. Linkage mapping of serotonin transporter gene SLC6A4 on chromosome 17. Hum Genet 95:677-680.

Graham D, Langer SZ 1992. Advances in sodium-ion coupled biogenic amine transporters. Life Sci 51:631-645.

Greenberg BD, Tolliver TJ, Huang S-J, Li Q, Bengel D, Murphy DL 1999. Genetic variation in the serotonin transporter promoter region affects serotonin uptake in human blood platelets. Am J Med Genet 88:83-87.

Handelsman L, Kahn RS, Sturiano C, Rinaldi PJ, Gabriel S, Schneidler JP, et al. 1998. Hostility is associated with a heightened prolactin response to meta-chlorophenylpiperazine in abstinent cocaine addicts. Psychiatry Res 80:1-12.

Hanna GL, Himle JA, Curtis GC, Koram DQ, Veenstra-VanderWeele J, Leventhal BL, et al. 1998. Serotonin transporter and seasonal variation in blood serotonin in families with obsessivecompulsive disorder. Neuropsychopharmacology 18:102-111.

Heils A, Teufel A, Petri S, Stober G, Riederer P, Bengel D, et al. 1996. Allelic variation of human serotonin transporter gene expression. J Neurochem 66:2621-2624.

Heinz A, Jones DW, Mazzanti C, Goldman D, Ragan P, Hommer D, et al. 2000. A relationship between serotonin transporter genotype and in vivo protein expression and alcohol neurotoxicity. Biol Psychiatry 47:643-649. 
Heidbreder CA, Oertle T, Feldon J 1999. Dopamine and serotonin imbalances in the left anterior cingulated and pyriform cortices following the repeated intermittent administration of cocaine. Neuroscience 89:701-715.

Humblot N, Thiriet N, Gobaille S, Aunis D, Zwiller J 1998. The serotonergic system modulates the cocaine-induced expression of the immediate early genes egr-1 and c-fos in rat brain. Ann NY Acad Sci 844:7-20.

Jacobsen LK, Staley JK, Malison RT, Zoghbi SS, Seibyl JP, Kosten TR, et al. 2000. Elevated central serotonin transporter binding availabilty in acutely abstinent cocaine-dependent patients. Am J Psychiatry 157:1134-1140.

Kaiser R, Muller-Oerlinghausen B, Filler D, Tremblay PB, Berghofer A, Roots I, et al. 2002. Correlation between serotonin uptake in human blood platelets with the 44-bp polymorphism and the 17-bp variable number of tandem repeat of the serotonin transporter. Am J Med Genet 114:323-328.

Kleven MS, Koek W 1998. Discriminative properties of cocaine: enhancement by monamine reuptake blockers. J Pharmacol Exper Ther 284:1015-1025.

Kranzler H, Lappalainen J, Nellissery M, Gelernter J 2002. Association study of alcoholism subtypes with a functional polymorphism in the serotonin transporter protein gene. Alcohol Clin Exp Res 26:1330-1335.

Lerman C, Shields PG, Audrain J, Main D, Cobb B, Boyd NR, Caporaso N 1998. The role of the serotonin transporter gene in cigarette smoking. Cancer Epidemiol Biomarkers Prev 7:253255.

Lesch K-P, Wolozin BL, Murphy DL, Reiderer P 1993. Primary structure of the human platelet serotonin uptake site: identity with the brain serotonin transporter. J Neurochem 60:2319-2322.

Lesch K-P, Balling U, Gross J, Wolozin BL, Riederer P, Murphy DL 1994. Organization of the human serotonin transporter gene. J Neural Transm 95:157-162.

Lesch K-P, Bengel D, Heils A, Sabol SZ, Greenberg BD, Petri S, et al. 1996. Association of anxiety related traits with a polymorphism in the serotonin transporter gene regulatory region. Science 274:1527-1531.

Lichtermann D, Hranilovic D, Trixler M, Franke P, Jernej B, Delmo CD, et al. 2000. Support for an association of a polymorphic site in the promoter region of the serotonin transporter gene with risk for alcohol dependence. Am J Psychiatry 157:2045-2047.

Little KY, McLaughlin DP, Zhang L, Livermore CS, Dalack GW, McFinton PR, et al. 1998. Cocaine, ethanol, and genotype effects on human midbrain serotonin transporter binding sites and mRNA levels. Am J Psychiatry 155:207-213.

Lowry O, Rosebrough NJ, Farr AL, Randall RJ 1951. Protein measurement with the Folin Phenol reagent. J Biol Chem 193:265-275.

McGue M, Pickens RW, Svikis DS 1992. Sex and age effects on the inheritance of alcohol problems: a twin study. J Abnormal Psychol 101:3-17.

McLellan AT, Luborsky L, Cacciola J, Kushner H, Peters L, Smith I, et al. 1992. The fifth edition of the Addiction Severity Index: cautions, additions and normative data. J Nervous Mental Dis 168:26-33. 
McMahon LR, Cunningham KA 2001. Antagonism of 5-hydroxytryptamine(2a) receptors attenuates the behavioral effects of cocaine in rats. J Pharmacol Exp Ther 297:357-363.

Mellerup E, Bennike B, Bolwig T, Dam H, Hasholt L, Jorgensen MB, et al. 2001. Platelet serotonin transporters and the transporter gene in control subjects unipolar patients and bipolar patients. Acta Psychiatr Scand 103:229-233.

Miller SA, Dykes D, Plessky HF 1988. A simple salting out procedure for extracting DNA from human nucleated cells (Letter). Nucl Acids Res 16:1215.

Naylor L, Dean B, Pereira A, Mackinnon A, Kouzmenko A, Copolov D 1998. No association between the serotonin transporter-linked promoter region polymorphism and either schizophrenia or density of the serotonin transporter in human hippocampus. Mol Med 4:671674.

Nemeroff CB, Knight DL, Franks J, Craighead WE, Krishnan KR 1994. Further studies on platelet serotonin transporter binding in depression. Am J Psychiatry 151:1623-1625.

Ozaki N, Rosenthal NE, Mazzola P, Chiueh CC, Hardin T, Garcia-Borreguero D, et al. 1994. Platelet $\left[{ }^{3} \mathrm{H}\right]$ paroxetine binding, 5-HT-stimulated $\mathrm{Ca}^{2+}$ response and 5-HT, content in winter seasonal affective disorder. Biol Psychiatry 36:458-466.

Patkar AA, Berrettini WH, Hoehe M, Hill KP, Sterling RC, Gottheil E, Weinstein SP 2001. Serotonin transporter (5-HTT) gene polymorphisms and cocaine dependence among AfricanAmerican individuals. Addict Biol 6:337-345.

Patkar AA, Gottheil E, Berrettini WH, Thornton CC, Hill KP, Weinstein SP 2003. Platelet tritiated paroxetine binding and treatment outcome among African-American cocaine dependent individuals. J Addict Dis 22:79-92.

Preuss UW, Soyka M, Bahlmann M, Wenzel K, Behrens S, de Jonge S, et al. 2000. Serotonin transporter gene regulatory region polymorphism (5HTTLPR), $\left[{ }^{3} \mathrm{H}\right]$ paroxetine binding in healthy control subjects and alcohol-dependent patients and their relationships to impulsivity. Psychiatry Res 96:51-61.

Sander T, Harms H, Lesch K-P, Defeu P, Kuhn S, Hoehe M, et al. 1997. Association analysis of regulatory variation of the serotonin transporter gene with severe alcohol dependence. Alcohol Clin Exp Res 21:1356-1359.

Schloss P, Williams DC 1998. The serotonin transporter: a primary target for antidepressant drugs. J Psychopharmacol 12:115-121.

Schuckit MA, Mazzanti C, Smith TL, Ahmed U, Radel M, Iwata N, et al. 1999. Selective genotyping for the role of 5-HT2A, 5-HT2C, and GABA alpha 6 receptors and the serotonin transporter in the level of response to alcohol: a pilot study. Biol Psychiatry 45:647-651.

Staley JK, Basile M, Flynn DD, Mash DC 1994. Visualizing dopamine and serotonin transporters in the human brain with the potent cocaine analogue $\left[{ }^{125} \mathrm{I}\right] \mathrm{RTI}-55$ : in vitro binding and characterization. J Neurochem 62:549-556.

Stoltenberg SF, Burmeister M 2000. Recent progress in psychiatric genetics-some hope but no hype. Hum Mol Genet 12:927-935. 
Stoltenberg SF, Twitchell GR, Hanna GL, Cook EH, Fitzgerald HE, Zucker RA, et al. 2002. Serotonin transporter promoter polymorphism, peripheral indices of serotonin function, and personality measures in families with alcoholism. Am J Med Genet 114:230-234.

Willeit M, Stastny J, Pirker W, Praschak-Rieder N, Neumeister A, Asenbaum S, et al. 2001. No evidence for in vivo regulation of midbrain serotonin transporter availability by serotonin transporter promoter gene polymorphism. Biol Psychiatry 50:8-12.

Zahniser NR, Doolen S 2001. Chronic and acute regulation of $\mathrm{Na}^{+} / \mathrm{Cl}$-dependent neurotransmitter transporters: drugs, substrates, presynaptic receptors, and signaling systems. Pharmacol Ther 92:21-55. 